\title{
Cognitive Evaluation of the Hierarchical Approach for Measuring Ego-centered Social Networks
}

\author{
Jana Nadoh $^{1}$, Petra Podreberšek ${ }^{2}$, and Valentina Hlebec ${ }^{3}$
}

\begin{abstract}
This paper explores how respondents understand and interpret Antonucci's hierarchical approach (Antonucci, 1986) for measuring egocentered social networks. Cognitive in-depth probes were used to assess how respondents (egos) differentiated among people (alters) that are named in hierarchical circles and what criteria they used to select people from their global social network.

In Antonucci's approach emotional criteria are used for selecting alters from the respondent's global network and placing them into three hierarchical circles that are graphically presented to the respondent. The respondent (ego) is at the center of the three circles. The more central the circle, the closer and more important are the people (alters) within it. The technique begins by asking the individual to look at the diagram of three concentric circles, with a smaller circle in the center containing the word 'You'. Respondents are told that the three circles should be thought of as including "people who are important in your life right now « but who are not necessarily equally close. Individuals in the inner circle are described as »those people to whom you feel so close that it is hard to imagine life without them. « The middle circle is described as »people to whom you may not feel quite that close but who are still important to you. « And finally, outer-circle members are $»$ people whom you haven't already mentioned but who are close enough and important enough in your life that they should be placed in your personal network. " (Antonucci, 1986). This procedure is often used in research on ego-centered support networks. Only one "name generator" is used for data collection, a technique which is more convenient for respondents and cheaper for the researcher.

Data were collected by face-to-face data collection mode with a convenient sample of 84 respondents. First, respondents filled in the Antonucci's measurement instrument, and second, they were asked to
\end{abstract}

\footnotetext{
${ }^{1}$ Faculty of Social Sciences, University of Ljubljana; jana.nadoh@fdv.uni-lj.si

${ }^{2}$ Faculty of Social Sciences, University of Ljubljana

${ }^{3}$ Faculty of Social Sciences, University of Ljubljana; valentina.hlebec@fdv.uni-lj.si
} 
evaluate the interpretation of the emotional criteria used to elicit the members of the ego-centered social network.

Analyses show that the respondents most often focused on types of ties (for example "I thought of - my family, my best friend,..."), quality of ties (for example "I cannot imagine my life without them." or "These are people that are close to me.") or formal characteristics of ties (for example "These are people I have regular contacts with.") regardless of the circle.

When focusing on the differences among people within circles, respondents gave three types of answers. Some focused on hierarchical differences between people (for example "In the inner circle is my family, in the second are good friends and in the third are acquaintances."); others focused on various characteristics of ties (for example "In the inner circle are people that are very close to me,..." or "I see most often,..." or "I have regular contacts,..."). Some respondents used different criteria at the same time. Some respondents established their own hierarchy among the circles (for example "I distinguish between the circles based on frequency of contacts, or closeness..."). Analyses also show that there are differences in interpretation depending on age of respondents, but not in relation to other demographic variables.

\section{Introduction}

Vaux (1988: 28-29) defines the social support network as a subset of the larger social network to which an individual turns or could turn for assistance. Support networks, i.e., social support network resources, are assumed to be stable in terms of size and composition, except in times of developmental transitions or nonnormative life changes. There are several indicators of support network characteristics that are related to the quantity and quality of social support provision offered to and received by an individual from their social support network, such as characteristics of ties linking an individual with the social network (intimacy, frequency of contacts, duration of relationship, strength of tie, negative contents, reciprocity, and role multiplexity) and several characteristics of support networks (density, composition, homogeneity, and dispersion) (McCallister and Fischer, 1983; Wellman, 1981; Marsden, 1987; Vaux, 1988; Wellman and Wortley, 1990; Goodenow, Reisine and Grady, 1990; Wellman et al. 1996; Silverstein et al., 2002).

In measuring social support networks, several steps have to be taken. Firstly, existing ties have to be identified, i.e., all alters with whom the focal ego has some sort of relationship. When all ties are identified, the contents of ties have to be evaluated, such as type support exchange. Secondly, the characteristics of ties such as strength, reciprocity and multiplexity have to be assessed. In most cases the characteristics of the alters are also measured. Identification of alters is done by network generators. A network generator is a question for eliciting the names of the alters of an ego's supportive network. 
Generally four distinctive criteria for inclusion of alters - i.e., support providers - can be used in network generators (van der Poel, 1993). Interaction, role-relation, affective, and exchange approaches are used to identify support providers. The affective approach uses the subjective value which a relationship has for a respondent, such as closeness, intimacy, or importance (van der Poel, 1993a). The affective approach was proposed by Antonucci (1986), where the criterion of closeness is used to distinguish three social support convoys. Along the dimension of closeness, as hypothesized by Antonucci, characteristics of social support providers change with respect to closeness, composition, and duration. The closest should be spouse, close family, and friends. Ties with these people are not likely to change in the short term period. The second convoy should represent role-related ties, such as those with the extended family and other relatives, friends, co-workers, and neighbors. The importance of these ties is more likely to change over time. The broadest circle represents the most distant ties with neighbors, co-workers, distant family, professionals, and supervisors. The connections with these people are most likely to be role-dependent and short term.

This method is simple, efficient and comprehensible to the general public. The purpose of the circle diagram is to provide respondents with some framework for the description of their social support network. On the other hand, this mapping method does not assume too rigid a structure. Many previous approaches simply equate the existence of social ties with warm, supportive interaction, which is a highly questionable assumption. On the other hand, the concentric circle diagram makes no assumptions about who is or should be a network member; it simply permits respondents to describe their social support networks according to their own personal feelings of closeness. One great advantage of this approach is that the series of questions used contains minimal bias or demand characteristic (Antonucci, 1986). They developed the concentric circle diagram as a visual image of a support network when they were preparing to go into the field with the first national American study of support networks of older adults in 1979.

The technique begins by asking the individual to look at the diagram of three concentric circles, wiht a smaller circle in the center containing the word 'You'. Each of the three circles is viewed as representing a different level of closeness to the focal person. Respondents are told that the three circles should be thought of as including »people who are important in your life right now « but who are not necessarily equally close. Individuals in the inner circle are viewed as the most important support providers and are described as »those people to whom you feel so close that it is hard to imagine life without them. "The middle circle is described as $»$ people to whom you may not feel quite that close but who are still important to you.« And finally, outer-circle members are »people whom you haven't already mentioned but who are close enough and important enough in your life that they should be placed in your personal network « (Antonucci, 1986).

In his research, adults aged 50 and older were then asked a series of questions concerning structural and functional characteristics of the first 10 people listed in 
their network. Structural characteristics included network size, age, sex, circle placement, relationship to the focal person (spouse, friends, relatives, etc., ...), number of years alters and the focal person have been known each other, frequency of contact, and distance between the focal person's and the alter's residence. They also measured six types of social support provided to and recived by the focal person: 1. confiding about things that are important, 2. being reassured when feeling uncertain, 3. being respected, 4. being cared for when ill, 5. talking with someone when upset, nervous or depressed, and 6. talking with someone about one's health (Antonucci and Akiyama, 1987).

Several authors compared and discussed four types of network name generators. Milardo (1989) compared affective and interactive network generators of spouses ${ }^{4}$. The affective criterion was closeness. The affective networks were much smaller than the interactive networks. There was only a $25 \%$ overlap in network membership. The affective approach - that is the name generator using discussion of important matters - gives small, strong-tie, affective networks as opposed to the reversed small world technique which gives larger, weak-tie, effective networks (Bernard et al., 1987). Persons that are discussion partners are most likely friends, relatives, and co-workers who are especially close to respondents. Discussion partners show a high degree of homogeneity with regard to sex, age, religion, and ethnicity (Burt, 1984; Marsden, 1988); Marsden 1987; Burt 1986). Bernard et al. (1990) compared discussion networks with the exchange networks obtained by McCallister and Fisher's name generators. In comparison to exchange networks, discussion networks are small. The affective approach (the 6 closest persons outside the home) was compared to the exchange approach (Fisher, 1982), and discussion networks (GSS, Marsden, 1987) with regard to network composition. Network size was most affected by the network generator, whereas the typical characteristics of alters within ego-centered networks - such as age, education, and sex - were not affected. However, heterogeneity was somewhat affected, with discussion networks being the most homogeneous. These three network generators also yielded different types of relationships with regard to the duration and frequency of contacts.

The exchange, affective, and role relationship approaches were compared by Sonderen et al. (1990). Approximately $73 \%$ of the affective network is also identified by the exchange approach, but only $46 \%$ of the exchange network is identified by the affective network. When comparing specific questions from the exchange approach with those from the affective approach (first and second convoy together), discussion of personal topics covered $90 \%$ of all relationships identified with the first and second convoys of affective networks. The authors conclude that affective network generators measure mostly long term relationships and highly valued ties, whereas the exchange approach measures those persons encountered regularly and frequently talked to, more alters of lower importance

\footnotetext{
${ }^{4}$ Milardo and Allan (1997) also describe the role of social support in marital relationships.
} 
and those known for a shorter time, but encountered more frequently within a closer living distance. The selection of an appropriate network generator is extremely important. Each of the approaches described measures a different type of relationship. When selecting the most efficient network generator, one has to be certain which kinds of socially supportive relationships are of primary interest.

When selecting the affective approach to measuring social support networks, one has to be aware of the subjective criteria used in eliciting names of social support providers. The subjective criteria can vary from respondent to respondent, and it is usually not controlled for in any way. Bailey and Marsden (1999) used the "think aloud" technique to evaluate subjective interpretations of the term "important matters" which is used in Burt's affective name generator. They found substantial variation in interpretation of this term, but luckily only small variations in the composition of the networks measured.

The purpose of our study is twofold. Firstly we would like to see how respondents interpret the term "closeness" used in Antonucci' hierarchical mapping approach to measure social support networks, how respondents (egos) differentiate among people (alters) that are named in the hierarchical circles and what criteria they use to select people from their global social network

\section{Method and Data}

Apart from measuring ego-centered social networks with Antonuccis' hierarchical mapping technique, we were interested in evaluation of the criteria used in the questionnaire. Respondents first answered questions about their ego-centered social networks. Cognitive probing ${ }^{5}$ was used at the end of the interview to assess the interpretation of the emotional criterion used to list members of the egocentered social network. For each circle the respondents were asked to describe what was going through their minds when eliciting the names, and to name the criteria used to select these people. Lastly the respondents were asked to describe the differences between people in the first, the second and the outer circle in their own words. Data were collected ${ }^{6}$ by face-to-face data collection mode with a convenient sample of 84 respondents (gender and age of respondents were fixed in advance). Extensive coding in two steps was necessary to sort meaningful answers to the cognitive probes. Analysis of variance was used to assess differences in measured ego-centered networks among respondents that used different criteria for listing alters.

\footnotetext{
${ }^{5}$ Exact wording is in Appendix.

${ }^{6}$ Data collection and coding was done by a group of students attending the Social network analysis and Questionnaire design courses in 2001/2002.
} 


\section{Results}

In order to evaluate the cognitive aspect of Antonucci's hierarchical approach, we studied the following questions:

Do respondents understand and interpret the hierarchical mapping technique in the same way as Antonucci predicted they would?

How do the respondents differentiate among people that are named in the hierarchical circles?

What are the criteria they use to select the people in their social network?

Are there any differences in measured networks for respondents that use different criteria for eliciting alters?

The convenient sample comprised 41 male and 43 female respondents; age varied from 19 to 82 (48\% within 19-26, 33\% within $27-50$ and $19 \%$ within 51 82). About $40 \%$ was married or living as married, about $53 \%$ single; $70 \%$ finished high school; $44 \%$ of them are still students).

Table 1: Pre-coded answers.

\begin{tabular}{|c|c|}
\hline Pre-coded Answers ${ }^{7}$ & Frequency \\
\hline \multicolumn{2}{|l|}{ Circle $1-180$ answers altogether } \\
\hline I thought of my immediate family (close family, close relatives). & 24 \\
\hline These are people that are the most (very) important for me. & 17 \\
\hline Life without these people would be very different. & 16 \\
\hline These are people that are very (most) close to me. & 16 \\
\hline We are in regular contact. & 16 \\
\hline These are very close friends. & 11 \\
\hline I thought about people I live with. & 10 \\
\hline \multicolumn{2}{|l|}{ Circle $2-131$ answers altogether } \\
\hline These are very close friends. & 20 \\
\hline I thought of my immediate family (close family, close relatives). & 18 \\
\hline We are in regular contact. & 16 \\
\hline These are people that are the most (very) important for me. & 10 \\
\hline \multicolumn{2}{|l|}{ Circle $3-129$ answers altogether } \\
\hline These are close friends. & 20 \\
\hline I thought of people I see less often than people in the other two circles. & 18 \\
\hline
\end{tabular}

The following results show what or who the respondents first thought of and how they selected alters when they were asked to sort the people from their social support network into three concentric circles. Among 84 respondents, some refused to give answers to cognitive probing. Therefore, we have 70 responses for the first circle, 62 responses for the middle circle and 60 responses for the third circle. Some respondents were rather talkative and gave more than one type of answer, some even as many as five assorted criteria. In order to fully assess the

\footnotetext{
${ }^{7}$ Only answers with a frequency of 10 or more are listed.
} 
richness of the answers obtained by cognitive probes, a multiple response counting technique was used as the first stage of analysis. Therefore, all given answers are taken into account for each respondent. The most frequently given pre-coded answers are presented in Table 1.

Answers presented in Table 1 show that the respondents talked either of types of ties, that is of the people they sorted in to each individual circle (for example "I thought of my family, my best friend"), quality of ties (for example "I cannot imagine my life without them." or "These are people that are close to me.") or formal characteristics of ties (for example "These are people I have regular contacts with."). There was a variety of answers that could not be interpreted in this way. The criteria of closeness that is given in the original name generator is either used (in)directly ${ }^{8}$ to describe quality or quantity of ties or transformed into types of ties. The first indicates the emotional criteria that should be used, and the second points to the result of the measurement instrument - measured network.

Let us see in Table 2 how often these types of answers appeared.

Table 2: Types of answers.

\begin{tabular}{|c|c|c|}
\hline Types of Answers & Frequency & Percentage \\
\hline \multicolumn{3}{|l|}{ Circle 1} \\
\hline Types of ties & 13 & 19 \\
\hline Characteristics of ties & 35 & 50 \\
\hline Mixed $^{9}$ & 21 & 30 \\
\hline Uncodable & 1 & 1 \\
\hline \multicolumn{3}{|l|}{ Circle 2} \\
\hline Types of ties & 10 & 16 \\
\hline Characteristics of ties & 27 & 44 \\
\hline Mixed & 24 & 39 \\
\hline Uncodable & 1 & 2 \\
\hline \multicolumn{3}{|l|}{ Circle 3} \\
\hline Types of ties & 10 & 17 \\
\hline Characteristics of ties & 31 & 52 \\
\hline Mixed & 19 & 32 \\
\hline Uncodable & 0 & 0 \\
\hline
\end{tabular}

It seems that the vast majority of respondents giving answers to the cognitive probes were able to provide answers that could be coded into three general categories. Even more, most of them focused on quality or quantity of ties and not on types of ties.

\footnotetext{
${ }^{8}$ Closeness is used interchangeably with "importance", "regularity of contacts". The second part of the name generator "cannot imagine your life without them" appeared in cognitive probing as "life would be different without them".

${ }^{9}$ Some respondents gave more elaborate answers that contained both types of answers - types of ties and characteristics of ties.
} 
Table 3: Types of answers in detail across circless.

\begin{tabular}{|c|c|c|c|}
\hline Types of answers & & & \\
\hline Characteristics of ties & Circle 1 & Circle 2 & Circle 3 \\
\hline Life without them would be different, difficult. & 29 & & \\
\hline People that are the most close to me. & 17 & & 13 \\
\hline People that are (most) very important to me. & 34 & 11 & 19 \\
\hline People that I like the most. & 14 & & \\
\hline People that I trust the most. & 20 & & \\
\hline People that I am in regular contact with. & 31 & 33 & \\
\hline People that I am not in regular contact with. & & & 32 \\
\hline People that help me. & 11 & 11 & \\
\hline People I cannot live without. & 9 & & \\
\hline People that support me for living. & & & \\
\hline People that make me feel good. & & 15 & \\
\hline People that are not as close to me as people in the inner & & 15 & 13 \\
\hline p circle. & & & \\
\hline People that support me emotionally. & & & \\
\hline Mixed & Circle 1 & Circle 2 & Circle 3 \\
\hline Life without them would be different, difficult. & 29 & & \\
\hline People that are the most close to me. & 38 & & \\
\hline People that are (most) very important to me. & 23 & 29 & 11 \\
\hline People that I like the most. & & & \\
\hline People that I trust the most. & & 13 & 16 \\
\hline People that I am in regular contact with. & 24 & 29 & \\
\hline People that I am not in regular contact with. & & & 37 \\
\hline People that help me. & 10 & & \\
\hline People I cannot live without. & 10 & & \\
\hline People that support me for living. & 14 & & \\
\hline People that make me feel good. & & & \\
\hline People that are not as close to me as people in the inner & & & 11 \\
\hline circle. & & & \\
\hline People that support me emotionally. & & 13 & \\
\hline (Close) family, relatives. & 67 & 55 & 16 \\
\hline (Close) friends. & 14 & 54 & 53 \\
\hline People I live with in the same household. & 29 & & \\
\hline Friends that I made recently, just friends. & & & 26 \\
\hline Acquaintances. & & & 16 \\
\hline Types of ties & Circle 1 & Circle 2 & Circle 3 \\
\hline (Close) family, relatives. & 77 & 60 & 50 \\
\hline (Close) friends. & 15 & 50 & 90 \\
\hline People I live with in the same household. & 31 & & \\
\hline $\begin{array}{r}\text { Friends that I made recently, just friends. } \\
\text { Acquaintances. }\end{array}$ & & & 10 \\
\hline
\end{tabular}


In Table 3 categories are closely examined. The table is organized in such way that all three circles can be compared at the same time. Therefore, we can see whether respondents actually used different criteria when listing alters within the three circles. One should note that percentages of cases obtained in the multiple response procedure are presented - the sum is usually higher than 100. Frequencies, presented in Table 2 are the basis for calculating the percentages in Table 3. For example, 29 percent of all respondents that gave answers only in the general category "Characteristics of ties", described people in the inner circle as people without whom life would be different and difficult. One has to be aware that most respondents gave several descriptions of the criteria they used and that the overall number of respondents in each category is small. Results should be interpreted in a qualitative way - one should look for patterns of answers appearing within each circle.

Respondents that gave answers only in the general category "Characteristics of ties" chose the most intensive descriptions for the inner circle - Circle 1. In circle one are those alters that are so important that respondents could not live without them, that are the most close ones, the most important ones, people that they trust, like the most and with whom they have regular contacts. "Closeness" and "life would be different without" them appear in the network generator - these two terms are taken directly from the wording. In other instances they are translated into feelings of importance, liking, trust and regularity of contact. Some important changes appear in the second circle. Two types of answers make reference to the people in the first circle, when describing alters in the middle circle - they are less close, and they mean less to respondents. Regularity of contacts is still among the most frequently given answers. There are references to exchange of social support - people that make me feel good, and we help each other. Among four categories that are the most frequent for the outer circle, two categories indicate further weakening of frequency of contacts and meaning to respondents. When comparing all three circles, a hierarchy of criteria, as hypothesized by Antonucci, can easily be observed.

Some respondents gave multiple answers that can be coded in both general categories - they appear in the general category "Mixed answers". The general pattern for "Characteristics of ties" is the same as above. A hierarchical distribution of criteria can easily be observed. Types of ties are also hierarchically distributed, with family being the most important in the first two circles and friends in the second and third. People from the same household as respondents are listed only in the first circle. Recently known friends and acquaintances are named only in the third circle. A similar pattern is present for respondents who gave answers only in the general category "Types of ties". One can say, that regardless of the terms used by respondents - types or characteristics of ties - a reduction in the degree of closeness is present.

We examined variations in selection of type of criteria across demographic variables. The crosstabulation of types of answers and age is presented in Table 4. 
It seems that younger respondents tend to describe the selection of alters more often with characteristics of ties and less often with type of tie. The group of respondents in the age range 27 to 50 years behaved similarly; however, the distribution of answers is more even across types of answers - mixed answers are quite frequent. Respondents in the older group chose characteristics of ties the least often, and they focused on types of ties or gave mixed answers more often. The differences are significant for the first circle. Similar results emerge for marital status and employment status. Nevertheless, these differences should not be interpreted in a substantive way - younger respondents tend to be students and not married. There were no differences across gender or education.

Table 4: Types of answers across age groups.

\begin{tabular}{|c|c|c|c|}
\hline Circle 1 & Age & & \\
\hline Type of answer & $18-26(\%)$ & $27-50(\%)$ & $51-82(\%)$ \\
\hline Type of tie & 6 & 27 & 36 \\
\hline Characteristics of tie & 70 & 41 & 21 \\
\hline Mixed & 24 & 32 & 43 \\
\hline$\chi^{2}=12.075$ & $\mathrm{p}=0.017$ & & \\
\hline \multicolumn{4}{|l|}{ Circle 2} \\
\hline Type of tie & 14 & 15 & 23 \\
\hline Characteristics of tie & 54 & 50 & 15 \\
\hline Mixed & 32 & 35 & 62 \\
\hline$\chi^{2}=5.693$ & $p=0.223$ & & \\
\hline \multicolumn{4}{|l|}{ Circle 3} \\
\hline Type of tie & 10 & 12 & 39 \\
\hline Characteristics of tie & 60 & 41 & 46 \\
\hline Mixed & 30 & 47 & 15 \\
\hline$\chi^{2}=7.979$ & $p=0.092$ & & \\
\hline
\end{tabular}

Finally we examined differences in the measured networks. Results of the analysis of variance are presented in Table 5. Several indicators of support networks, support behavior and support appraisal were selected and assessed in all three circles:

1. Characteristics of ties among respondents and their alters:

- Frequency of contact (on a scale from 1- live together - to 4 - have contact monthly or less often);

- Duration of ties (number of years they have known each other in categories on a scale from 1 - less than 5 years, 2 - five to ten years, 3 - ten to twenty years, 4 - more than 20 years);

- Multiplexity of ties, assessed as the number of different social support functions given and received by respondent;

2. Characteristics of support networks: 
- The size of support networks, measured as the number of alters listed within each circle;

- The composition of support networks, measured in the proportions of females and males, of kin or friends among the listed alters, and the average age of alters.

Table 5: Analysis of variance.

\begin{tabular}{|c|c|c|c|}
\hline Type of answer & Type of tie & $\begin{array}{l}\text { Characteristics } \\
\text { of tie }\end{array}$ & Mixed \\
\hline \multicolumn{4}{|l|}{ Circle 1} \\
\hline Duration of tie (\% of alters known 5-10 years). & 0 & 18 & 11 \\
\hline $\mathrm{F}=4.216$ & $\mathrm{p}=0.019$ & & \\
\hline Percentage of alters that live with respondent. & 72 & 43 & 60 \\
\hline $\mathrm{F}=3.833$ & $\mathrm{p}=0.027$ & & \\
\hline $\begin{array}{r}\text { Number of support functions provided by } \\
\text { respondent. }\end{array}$ & 4.3 & 4.5 & 3.8 \\
\hline $\mathrm{F}=2.281$ & $\mathrm{p}=0.110$ & & \\
\hline \multicolumn{4}{|l|}{ Circle 2} \\
\hline $\begin{array}{r}\text { Duration of tie (\% of alters known less than } 5 \\
\text { years). }\end{array}$ & 12 & 40 & 12 \\
\hline $\mathrm{F}=7.949$ & $\mathrm{p}=0.001$ & & \\
\hline Percentage of alters that live with respondent. & 25 & 6 & 11 \\
\hline $\mathrm{F}=2.997$ & $\mathrm{p}=0.058$ & & \\
\hline $\begin{array}{r}\% \text { of alters that are in weekly contact with } \\
\text { respondent. }\end{array}$ & 31 & 51 & 32 \\
\hline $\mathrm{F}=2.424$ & $\mathrm{p}=0.098$ & & \\
\hline $\begin{array}{r}\text { Number of support functions provided by } \\
\text { respondent. }\end{array}$ & 4.3 & 3.0 & 2.7 \\
\hline $\mathrm{F}=9.371$ & $\mathrm{p}=0.006$ & & \\
\hline $\begin{array}{r}\text { Number of support functions received by } \\
\text { respondent. }\end{array}$ & 3.6 & 2.4 & 2.6 \\
\hline $\mathrm{F}=2.467$ & $\mathrm{p}=0.094$ & & \\
\hline Percentage of relatives. & 62 & 35 & 58 \\
\hline $\mathrm{F}=3.029$ & $\mathrm{p}=0.056$ & & \\
\hline Percentage of friends. & 38 & 65 & 42 \\
\hline Average age of alters. & $\mathrm{p}=0.056$ & & \\
\hline Average age of alters. & 46 & 34 & 40 \\
\hline $\mathrm{F}=3.198$ & $\mathrm{p}=0.048$ & & \\
\hline
\end{tabular}

Most of the statistically significant ${ }^{10}$ differences between the three groups of respondents were observed in the second circle, some in the inner circle and none in the third circle. Only significant results are presented in the Table 5. In the inner circle significant difference appears for duration of ties and frequency of contacts -

\footnotetext{
${ }^{10}$ Since the number of respondents in each group is very small, we consider all results with $\mathrm{p} \leq 0.10$ as significant.
} 
but only in the category, and in number of support functions provided by respondents. The same variables are significant in the middle circle as well as some others - percentage of relatives, friends and average age of alters. We have to keep in mind that there were also differences in age. To combine substantive analysis with methodological, we calculated the average age of respondents who gave various cognitive answers for the second circle. The average age of respondents who gave cognitive answers within the category "types of ties" was 37 years; the average age of respondents who gave cognitive answers within the category "Characteristics of ties" was 31 years, and the average age of who gave mixed answers was 42 years.

Alters in the inner circle should be those that are closest to respondents, so it is not surprising that the majority should live with respondents. However, the youngest group of respondents (average age 31 ) has only 43 percent of alters living with them. This can be easily explained by reference to the part of the life cycle they currently occupy. They are more likely to be single and to be without their own family and children. Significant differences with regard to duration of ties and number of support functions are difficult to explain.

In the middle circle one should find typical support providers, still quite close to respondents, but likely to change a with change in role status. Therefore it is not surprising that the youngest group - the one that focused only on characteristics of ties - has the largest proportion of alters that have been known for less than five years. They have the smallest proportion of alters from the middle circle still living with them, and the largest proportion of alters seen weekly. They also provide and receive a small number of support functions. On the other hand, respondents whose average age is 37 are those that provide and give the largest number of support functions on average - it is plausible that these are the ones who have families with (younger) children, and therefore have a more lively exchange of social support. The percentage of relatives is the smallest in the youngest group, and the percentage of friends in the middle circle is the largest this is again easily explained by their age. Analogously, the average age of alters is the lowest in this group. As noted above, there are no significant differences in the outer circle.

\section{Discussion}

Cognitive probing was used to examine the understanding and interpretation of the network generator designed by Antonucci. The results of our study show that respondents understand the inherently hierarchical construction of this network generator. There appear to be three major groups of respondents: (1) those that interpret the criterion of closeness as one involving the quality of ties, (2) those that translate it into the type of tie, and (3) those that use both categories of meaning. There are some differences in these three groups of respondents with 
regard to their age. Gender has no effect on the interpretation of closeness in our study. The group of respondents that focused only on quality of ties is the youngest group; the group that focused only on types of ties is the middle group, and the last group - that used mixed criteria - is the oldest one.

It appears that there are also some significant differences in characteristics of he measured networks. To summarize, some significant variability with regard to the three groups of respondents appears for the inner circle, many for the middle circle and none for the outer circle. It seems that, regardless of any distinctive interpretation of the name generator, the closest alters are similar, and therefore also the characteristics of measured networks. In the middle circle are placed alters that provide social support and, since the three groups of respondents differ in average age, their support convoys should also differ. There are no significant variations in the outer circle, and it is hard to tell whether this is the consequence of small sample size or of the fact that there are no substantive variations.

It seems that younger respondents who are in the middle of their studies or have just completed them, are in the process of changing their social network composition. Therefore, when asked about the interpretation of closeness, they think about the quality and quantity of these ties instead of types of ties. Older respondents, with a stable network composition, have translated quality of ties into types of ties that are present in their networks. The last group - average age 42, that gave mixed answers, could again be at the stage of rethinking social network composition and close ties and therefore have provided a mixture of quality of ties and type of ties answers. Nevertheless, further analysis is needed to support these hypotheses and to confirm that this is a general trend not only an isolated finding of this study.

Our sample was a convenient sample. Even if we have 60 answers to cognitive probing, results cannot be generalized to the general population. Additional testing should reveal if our findings are reliable.

\section{Appendix: Cognitive probes}

Just before we finish this interview, let us think back to the first question in this interview; this is the question with the diagram.

F1. In the inner circle you selected people that you feel so close to that it's hard to imagine life without them.

What was your first thought when I asked you about these people?

How did you select these people?

F2. In the middle circle there are people that you don't feel quite that close to, but who are still important to you. 
What was your first thought when I asked you about these people?

How did you select these people?

F3. In the outer circle there are people to whom you feel less close, but who are still important to you.

What was your first thought when I asked you about these people?

How did you select these people?

F4. In your own words, how would you describe the differences between people in the first, second and the third circle?

\section{References}

[1] Antonucci, T.C. (1986): Measuring social support networks: Hierarchical mapping technique. Generations, 3, 10-12.

[2] Antonucci, T.C. and Akiyama, H. (1987): Social networks in adultl life and a preliminary examination of the Convoy model. The Gerontological Society of America, 519-527.

[3] Bailey, S. and P.V. Marsden (1999): Interpretation and Interview Context: Examining the General Social Survey Name Generator Using Cognitive Methods. Social Networks, 21, 287-309.

[4] Bernard, R.H., Shelley, G.A., and Killworth, P.D. (1987): How much of a network does the GSS and RSW dredge up? Social Networks, 9, 49-61.

[5] Bernard, R.H., et al. (1990): Comparing four different methods for measuring personal social networks. Social Networks, 12, 179-215.

[6] Burt, R.S. (1984): Network items and the general social survey. Social Networks, 6, 293-339.

[7] Burt, R.S. (1986): A note on sociometric order in the General Social Survey network data. Social Networks, 8, 149-174.

[8] Fisher, C.S. (1982): To Dwell Among Friends: Personal Networks in Town and City. Chicago: The University of Chicago Press.

[9] Goodenow, C., Reisine, S.T., and Grady, K.E., (1990): Quality of social support and associated social and psychological functioning in women with rheumatoid arthritis. Health Psychology, 9, 266-284.

[10] Marsden, P.V. (1987): Core discussion networks of Americans. American Sociological Review, 52, 122-31. 
[11] McCallister, L. and Fisher, C.S. (1983): A procedure for surveying personal networks. In Burt, R.S., and Minor, M.J. (Eds.): Applied Network Analysis: A Methodological Introduction. Beverly Hills: Sage, 75-88.

[12] Milardo, R.M. (1989): Theoretical and methodological issues in the identification of the social networks of spouses. Journal of Marriage and the Family, 51, 165-174.

[13] Silverstein, M., S.J. Conroy, H. Wang, R. Giarrusso, and V.L. Bengston (2002): Reciprocity of parent-child relationships over the adult life course. Journal of Gerontology, 57, S3-S13.

[14] van der Poel, M. (1993): Personal Networks: A Rational Choice Explanation of their Size and Composition. Lisse: Swets and Zeitlinger.

[15] van der Poel, M. (1993a): Delineating personal support networks. Social Networks, 15, 49-70.

[16] van Sonderen, E. et al. (1990): Personal network delineation: a comparison of the exchange, affective and role-relation approach. In C.P.M. Knipscheer and T.C. Antonucci (Eds.): Network Research: Substantive Issues and Methodological Questions. Amsterdam: Swets \& Zeitlinger, 101-120.

[17] Vaux, A. (1988): Social Support: Theory, Research, and Intervention. New York: Praeger Publishers.

[18] Wellman, B. (1981): Applying network analysis to the study of support. In B. H. Gottlieb (Ed.): Social Networks and Social Support, 171-200. Beverly Hills: Sage Publications.

[19] Wellman, B. and S. Wortley (1990): Different strokes from different folks: Community ties and social support. American Journal of Sociology, 96, 55888 .

[20] Wellman, B., Salaff, J., Dimitrova, D., Garton, L., Gulia, M., and Haythornthwaite, C. (1996): Computer networks as social networks: Collaborative work, telework, and virtual community. Annual Review of Sociology, 22, 231-38. 